\title{
Students' exploring and refining their equity ethic within the Access Network
}

\author{
Fidel Amezcua \\ Department of Chemical \& Biomolecular Engineering, \\ Georgia Institute of Technology, North Avenue, Atlanta, GA 30332 \\ Gina M. Quan \\ Department of Physics \& Astronomy, San José State University, San José, CA, 95192-0106 \\ Chandra A. Turpen \\ Department of Physics, University of Maryland, College Park, MD 20742
}

The Access Network is an organization that supports vibrant interactions among students and faculty who advocate for equity work in the physical sciences. This paper uses McGee and Bentley's framework of "equity ethic" (EE) to understand how Access student leaders adopt and refine a commitment to equity and social justice work within the physical sciences. In McGee and Bentley's study of STEM students of color, they define EE as students' sense of altruism and collectivism within and outside of their communities. Through interviews with student leaders, we model components of students' EEs and how their EEs are influenced by their participation in Access. Student accounts illustrate that they are invested in improving equity within their disciplinary communities and see progress toward these goals as an important measure of success. Our findings highlight how students are already infusing an EE into their professional physics activities. This research suggests that student leaders benefit from having opportunities to articulate and refine critiques of disciplinary culture, and connect their EE to their professional practices. These accounts suggest that this work occurs in conversation with other equity leaders around issues of social justice.

\footnotetext{
2020 PERC Proceedings edited by Wolf, Bennett, and Frank; Peer-reviewed, doi.org/10.1119/perc.2020.pr.Amezcua Published by the American Association of Physics Teachers under a Creative Commons Attribution 4.0 license. Further distribution must maintain the cover page and attribution to the article's authors.
} 


\section{INTRODUCTION}

There exist numerous efforts to improve equity in the physical sciences. These efforts have been initiated and led by people occupying many roles (e.g., students, faculty, staff, administrators) with many goals in mind (e.g., increase retention, improve culture, reduce structural bias) (e.g., [1-5]). In the context of efforts led by undergraduate and graduate students interested in cultivating supportive communities, we know little about how student leaders come to engage in equity work, the challenges they encounter, and the resources they draw on. Understanding how to support these student leaders is an important step toward improving their effectiveness and increasing equity.

The Access Network is an organization that supports physical science students in leading equity efforts within their local university departments $[1,6]$. Students in Access take on leadership roles not only locally, but also within the national network, shaping the organization's activities. This paper studies two student leaders in Access to understand how they engage in equity work through the lens of McGee and Bentley's construct of equity ethic [7].

\section{EQUITY ETHIC}

McGee and Bentley define an equity ethic (EE) as students' "principled concern for social justice and for the well-being of people who are suffering from various inequities" ([7], pg. 6) in their study of successful undergraduate Black and Latinx students majoring in STEM. EE is composed of two overlapping components: altruism-the desire to help those outside of one's community - and collectivism - the desire to help those within one's community. EE can be manifested in students' lives through a number of ways, including a desire to be a role model for one's community, spending free time volunteering, and a desire to use STEM knowledge to help others. Students in McGee and Bentley's study often experienced their EE in tension with their professional life, ultimately leading some to consider leaving STEM. This research complements other studies showing that white women and students of color often experience tensions between professional STEM work and a desire to help others [8-11].

Within our work, professional practice refers to the set of interconnected, purposeful activities that students engage in as scientists $[12,13]$. Creating opportunities for physical science students, particularly those from marginalized backgrounds, to blend their EE with their professional practice can impact their likelihood to continue in STEM [14, 15]. In this PERC paper, we aim to understand the equity ethic (EE) of student leaders within Access and how their EE is refined through participation in Access. Through focusing on two students, Keith and Cruz (pseudonyms), this pilot study provides insight into the following research questions:

(RQ1): How have students' senses of altruism and collectivism evolved within the context of Access?
(RQ2): How do students enact altruism and collectivism in their professional practice?

\section{THE ACCESS NETWORK}

The Access Network is an organization that supports vibrant interactions between students and faculty working toward increasing equity in the physical sciences $[1,6]$. The network's primary goals are to support equity within the sciences, create meaningful opportunities for students to lead equity efforts, and work toward a physical science culture where equity and justice are foregrounded. The network consists of nine university-based programs, referred to as "sites." Each of these sites run their own set of activities at their local institutions (e.g., mentoring, early-start summer programs, socials) [16-22].

Students in Access play a central role in the network's organizing activities designed to support equity and community building. At the network level, a team of Assembly Fellows (one student per site) plans the network's annual in-person gathering, or "Assembly." The Assembly's purpose is to exchange ideas, support the professional development of one another, and expand members' understanding of social justice issues. A team of Network Fellows (also one per site) act as liaisons between sites and the network, oversee travel between sites, and manage network communications. The student fellows are mentored into their roles by faculty, postdoctoral, and graduate student leaders in the network. The students who become involved at the network-level often start out participating in site-level activities, and gradually become more involved in the national community. Since network's formation in 2015, over 100 students have participated in network-related activities such as the Assembly, fellowships, and other professional development experiences.

\section{OUR STUDY AND METHODS}

In this pilot study, F. Amezcua conducted online interviews with nine Access student leaders focusing on their experience within Access, their goals around equity and social justice, and the experiences that shaped these goals. These interviews were semi-structured, and the emergent storytelling influenced the topics discussed. The interviewer shared aspects of his own life experiences, where he saw points of connection. This contributed to a friendly and collegial atmosphere in the interviews. We invited student leaders with at least moderate involvement in Access at the network-level (serving one or more terms as a fellow or attending one or more Assemblies) to be interviewed. We prioritized interviewing students of color, and 5/9 interviewees were students of color.

This analysis focuses on two interview participants, Cruz and Keith. At the time of the interviews, both had served one term as a Network Fellow and had attended one Access Assembly. We focused our early phases of analysis on these 
interviews because F. Amezcua recalled these conversations as particularly rich.

Keith is a graduate student and active in his local site. He identifies as an African American/Black man. Cruz is currently a graduate student at a campus not affiliated with Access, but was an undergraduate student at his local site when he was involved in Access. Cruz identifies as a Hispanic man.

\section{A. Researcher Positionality}

All three authors have been highly engaged in Access for the past several years. F. Amezcua previously served as a Network Fellow as an undergraduate student at Chicago State University. G. Quan and C. Turpen have mentored the cohorts of Network Fellows that Keith and/or Cruz participated in. All authors have attended multiple Assemblies, including those which Cruz and Keith attended. This history of co-organizing with the participants gives us context for interpreting their stories and contributes to increased trust and some shared understanding with them. We orient toward our research with a sense of solidarity with our participants as well as a commitment toward the growth of the organization.

F. Amezcua is a Mexican American cisman, C. Turpen is white ciswoman, and G. Quan is a Chinese American ciswoman. Though not a focus of this paper, reflection on our identities have been relevant toward understanding interview dynamics and our interpretations of the conversations.

\section{B. Analysis}

All 9 interviews were professionally transcribed. We collaboratively went through several interviews line-by-line to flag lines related to EE and discuss themes related to EE. Through these discussions we became particularly interested in how students were already integrating their EEs into their professional work, a theme that became labeled professional practice. Using a spreadsheet, we progressively refined our analysis [23, 24] through collaboratively analyzing transcript segments related to collectivism, altruism, and professional practice. We developed timelines and analytic memos for Keith and Cruz to help us make sense of the data.

We found that Keith's and Cruz's evolving EEs are made visible in their commitment to cultural change in physics (RQ1), their desire to create more supportive college learning experiences for others (particularly for students of color) (RQ1), and their expansive forms of professional practice (RQ2). We will discuss each of these themes in turn.

\section{RQ1: COMMITMENT TO CULTURAL CHANGE IN PHYSICS}

Our first theme is a "commitment to cultural change in physics." We show two examples of this theme, and discuss how exploration and refinement of this aspect of students' EEs is informed by their participation in Access.

One crucial aspect of Keith's EE emerges in his descriptions of how Access helped him identify his desire to bring about a "cultural revolution" to the field of physics, or as he calls it, his "big lofty goal." During an Access Assembly, Keith had the opportunity to interact with various site leaders informally. In the following quote, Keith discusses how these conversations informed his goal of working in a social justice space that focuses on persistent issues in the academy:

[D]uring the Access Assembly this past summer, we were sitting in the hotel lobby, and ...we were essentially talking about what exactly ...our big goal was in tackling problems like increasing retention in underrepresented minorities. And this conversation made it very clear to me that ultimately, my big goal, which is constantly being reinforced by being in ...being a part of Access and being a part of [site] is to have a big paradigm shift, like a cultural revolution, in how people see science, specifically physics...

Here we see one example of how meaningful conversations with Access leaders allowed Keith to further clarify his personal and collective goal of enacting change. It is evident that Keith's continuous engagement with the network and his site positively reinforced his objectives, ideas, and desires to pursue aspects of his EE. He was able to formulate a specific, long term, career philosophy that, as we will see in future sections, drives his desire to change the world around him. Keith then describes a desire to change physics culture and the general perception that physics is a white discipline:

[L]et's face it, if you think physicists, you go to anyone, any person on the street, and you think this just... that the figure that comes to mind is old, white guy. And it'd be cool if that wasn't the case. So yes, that big, lofty goal is entirely because I joined [site] and Access.

Keith's EE applies to both changing the culture of physics and changing how it is perceived. Here, Keith is critiquing the lack of diversity within physics. This critique is further supported in sections of the interview where Keith elaborates his commitment to creating opportunities for other students of color (section VI). We argue that his local site and Access play an essential role in influencing his understanding of equity and further developing his goals related to cultural change.

Through Cruz's experience within Access, Cruz realizes that furthering his education and going to graduate school would allow him to change the culture of physics. At the time of his interview, Cruz was in his first year of graduate school; however, he retrospectively gave accounts of how his site and Access influenced his educational trajectory. The following excerpt focuses on Cruz's emerging EE and 
expresses the need for people to step into leadership roles and change the reputation of the field of physics:

The issue of the whole field having a negative reputation. A bunch of super-smart people that don't know how to communicate and then when you don't get it, then they chastise you. I, fortunately, did not have a negative experience like that but I've heard stories. So, those two things have really changed the way I look at the field and it's demonstrated that there need to be people in the field to change that stuff... after joining my site, I realized it's almost imperative that I stay in the field and that way I could help make a difference in some way. Maybe tiny, but in some way.

Cruz's interactions with his site created opportunities for him to generate career objectives that overlapped with his EE at the graduate level. Through these interactions, Cruz realized that he wanted to pursue a graduate degree, but that it was also "imperative" for him to continue studying within his field to make an impact. Cruz also understands the negative reputation associated with physics, and he takes it upon himself to pursue a career and education that cater to changing that culture of physics. We see that this commitment to shifting perceptions of the field is tied to his experience as a POC in physics (elaborated in section VI) as well as his deliberate approach to teaching (elaborated in section VII).

\section{RQ1: CULTIVATING SUPPORTIVE LEARNING EXPERIENCES FOR PHYSICS STUDENTS OF COLOR}

We now provide two examples of a theme we describe as "cultivating supportive college learning experiences for students of color in physics," and discuss how this theme is informed by students' participation in Access.

Keith began studying physics in an undergraduate program where white women and people of color were prevalent. In graduate school, Keith has come to see his own learning experiences within a supportive undergraduate program as uncommon for many students of color. Keith wants to help expand such opportunities to more students of color and mentioned: "...the typical kind of adversity that you hear about that people of color have to face in the STEM field, I haven't had to face. And because I've had, so to speak, smooth sailing, I want to enable smooth sailing for other people." Keith articulates a collectivist vision of creating "smooth sailing" for others, particularly students of color that rarely encounter smooth seas. Now at a predominantly white institution, Keith sees his local Access site as contributing to his growing awareness and commitment to equity issues. In the following quote, he describes this commitment:

I became more aware primarily because the topics that we discuss in our [site] class are geared to social and systemic issues that people of color and women face in the STEM field. ...I became... far, far more passionate about doing something... This is my most active extracurricular activity that I do at my school and that I want to try to make part of my career.

Here Keith attributes his increasing awareness of the social and systemic issues facing students of color in STEM to a course offered by his local site. He notes that his experiences in his local site compounded his passion for these issues.

A second example comes from Cruz, who wants more support to be offered for first-generation students as they navigate college. In the following quote, he describes how this altruistic desire is grounded in his own experiences:

I was already aware that first-generation students don't necessarily have contacts on how college works. So, I was more interested in helping people who don't have the resources, like parents who went to college to really guide them through all of that stuff. ...I came in and I learned very late about grad school and jobs, and how intense the workload was. So... they [local site leaders] want to help students that don't have the resources, that's more what I was going to put my time and effort into. ...But we were physics so we kind of just stuck to physics, trying to recruit and then maintain Hispanic, Black, and female students.

Here we see evidence of Cruz's sense of collectivism with first-generation college students, students of color, and women, grounded in part in his own lived experiences. We see Cruz's sense of altruism toward increasing firstgeneration college students' access to "contacts" that can support navigation of spaces in higher education and retaining students of color in physics.

Later in the interview, Cruz discusses how his undergraduate instructors were friendly and invested in their teaching. Now that Cruz is a graduate student at a different institution, he has a new appreciation for this investment in teaching. These undergraduate experiences alongside formative experiences within Access set a foundation for Cruz to extend his EE into his own teaching work (see section VII).

\section{RQ2: TAKING ACTION IN PROFESSIONAL PRACTICE}

This section shows how Keith and Cruz enact their EE into their professional practice, but in different ways-Keith through building sustainable organizations, and Cruz through his inclusive teaching practices. Recall, professional practice refers to the set of interconnected, purposeful activities that students engage in as scientists.

Keith sees his experiences in both his local site and Access as enhancing the professional skills he can use to pursue his equity agenda. Keith's EE intertwines with his professional goal of building sustainable organizations that 
increase equity. He states, "I have this deep appreciation for building strong organizations... And that's one of the reasons I like working with [site]." He goes on to also describe his involvement as an Network Fellow in Access: "One of the things we did this summer was ... to build the foundation ... for future iterations of Network Fellows... I want to do precisely that of building a firm foundation for an organization to operate on." This goal felt especially relevant to Keith, as he had founded organizations as an undergraduate student that have now gone dormant. Keith elaborates on this altruistic professional goal:

And the whole point of creating these kinds of organizations is for the benefit of other people and especially now [site] where our goal is really to increase retention. If, after four years, a certain cohort leaves and the entire thing falls apart, then whatever efforts that cohort had made to establish this program were for naught. And so then the idea is to establish an organization that can continue to thrive and continue to provide the opportunities that the founders sought out for many more cohorts to come.

This quote shows how Keith's EE informs his efforts to improve an organization's sustainability and strength so that it can make a long-term impact. Across these quotations, Keith recounts his experiences in Access as helping him to learn how to build strong organizations that can sustain themselves beyond any one student's term. He is committed to seeing other students benefit from the local site's programming. In Keith's view, sustaining organizations allows them to improve in their pursuit of equitable impacts. Keith expresses his developing passion for growing strong, sustainable equity organizations and sees his capacity for such work as growing through his involvement in Access.

Similarly, Cruz's EE influences his professional practice as a graduate teaching assistant by informing how he builds classroom culture and relationships with students. In the following quote, Cruz describes how Access made him want to go beyond being "friendly" to also being "inclusive:"

I wanted to make [my teaching] friendly but I think after being a part of Access an adjective that I would not have probably said would be inclusive. It's something that you have to be mindful of and so if I didn't really think about it then I couldn't really implement it ... This idea of safe spaces like an inclusive environment. In the back of my mind, I didn't know what to call it until it was presented to me... If you just make it friendly, you're missing out on some of the key things that make people feel comfortable, and willing to learn, and more enthusiastic about learning.

To Cruz, inclusiveness connects to the idea of a "safe space" and whether everyone is comfortable. This mindful attention to inclusion is reflective of an altruistic orientation toward his students. He attributes his understanding of "inclusive" to his participation in Access.

Cruz later elaborated on how Access helped him better understand the diversity of individuals' experiences:

I remember going to some workshops about specifically talking about different issues and different people's perspectives, and things I didn't really-I don't know what it's like because I'm not them. So, I would yes, I'm a little bit more mindful thanks to Access to be-I guess in terms of being able to not necessarily understand someone else's experience or their issues, but being able to somehow connect that to your own... I think it definitely feeds into the teaching.

Cruz describes how Access created opportunities to understand different experiences and empathetically connect those with his own. He explains how this informed his teaching philosophy that a more comfortable learning environment can affect students' engagement in physics.

\section{DISCUSSION}

In this paper, we presented two themes that emerged from student interviews describing how students' EE evolved within the context of Access-a commitment to cultural change, and an interest in cultivating supportive learning experiences for physics students of color. We then showed how EE can be enacted in professional practice.

Keith and Cruz critiqued the current state of physics culture and actively contested it by engaging in different forms of professional work. They describe how this objective became refined in the context of Access-both from site/network-led activities focused on social justice, and in conversations with other equity leaders. For Keith, pursuing cultural change at a systemic level became his overarching objective. His desire to create sustainable equity-focused organizations reflects altruism toward POC and women in STEM as well as a collectivist desire to facilitate "smooth sailing" for a community he identifies with-African Americans. Similarly, Cruz is invested in changing physics culture at an interpersonal level. Cruz works to create a safe and inclusive space for undergraduate students in his classroom. Much like Keith, Cruz's actions and application of his EE to his professional work reflect altruism toward his students and a collectivistic desire to create an inclusive atmosphere for a population he identifies with-Hispanics. In both cases, we see that altruism and collectivism can sometimes become blended, a phenomenon noted by McGee and Bentley [6].

This paper reflects our pilot work documenting how students' EEs evolve within the context of Access and understanding how students enact EE in their professional practices. In future work, we plan to explore the nature of collectivism and altruism more deeply, as well as understand how particular Access experiences shape one's EE. 
[1] G. Quan, B. Gutmann, J. Corbo, B. Pollard, C. Turpen, and T. A. Network (2019).

[2] A. R. Daane, S. R. Decker, and V. Sawtelle, The Physics Teacher 55, 328 (2017).

[3] T. Hodapp and E. Brown (2018).

[4] G. White (2016).

[5] A. M. Porter and R. Ivie, AIP Statistical Research Center (2019).

[6] D. L. Reinholz, A. Corrales, and A. Stone-Johnstone, International Journal for Students As Partners 3, 44 (2019).

[7] E. McGee and L. Bentley, American Journal of Education 124, 1 (2017).

[8] E. Seymour and N. M. Hewitt, Talking about leaving (Westview Press, Boulder, CO, 1997).

[9] M. Ong, Social problems 52, 593 (2005).

[10] J. G. Stout, V. A. Grunberg, and T. A. Ito, Sex Roles 75, 490 (2016).

[11] G. Potvin, C. McGough, L. Benson, H. J. Boone, J. Doyle, A. Godwin, A. Kirn, B. Ma, J. Rohde, M. Ross, et al., IEEE Transactions on Education 61, 298 (2018).

[12] M. J. Ford, Science Education (2015).

[13] Authors and Collaborators ().

[14] N. M. Stephens, S. A. Fryberg, H. R. Markus, C. S. Johnson, and R. Covarrubias, Journal of personality and social psychology 102, 1178 (2012).

[15] J. Page-Reeves, A. Marin, M. Moffett, K. DeerInWater, and
D. Medin, Cultural Studies of Science Education 14, 177 (2019).

[16] M. S. Sabella, K. L. Mardis, N. Sanders, and A. Little, The Physics Teacher 55, 350 (2017).

[17] N.-K. Marks and R. Dawod, DePaul Discoveries 5, 22 (2016).

[18] C. Bertram, A. Leak, E. C. Sayre, M. B. Kustusch, and S. V. Franklin, in Transforming Learning, Empowering Learners: The International Conference of the Learning Sciences (ICLS) (International Society of the Learning Sciences, 2016).

[19] B. F. Albanna, J. C. Corbo, D. R. Dounas-Frazer, A. Little, and A. M. Zaniewski, in AIP Conference Proceedings (AIP, 2013), vol. 1513, pp. 7-10.

[20] P. R. Gandhi, J. A. Livezey, A. M. Zaniewski, D. L. Reinholz, and D. R. Dounas-Frazer, American Journal of Physics 84, 696 (2016).

[21] D. Dounas-Frazer, J. Lynn, A. Zaniewski, and N. Roth, The Physics Teacher 51, 32 (2013).

[22] D. R. Dounas-Frazer, S. A. Hyater-Adams, and D. L. Reinholz, The Physics Teacher 55, 342 (2017).

[23] R. A. Engle, F. R. Conant, and J. G. Greeno, in Video research in the learning sciences, edited by R. Goldman, R. Pea, B. Barron, and S. J. Derry (Routledge, New York, NY, 2007), pp. 239-254.

[24] J. P. Spradley, The ethnographic interview (Waveland Press, 2016) 